\title{
Horizontal bulk material pressure in silo subjected to impulsive load
}

\author{
Radosław Tatko ${ }^{\mathrm{a}, *}$ and Sylwester Kobielak ${ }^{\mathrm{b}}$ \\ ${ }^{a}$ The Faculty of Environmental Engineering and Geodesy, Wroclaw University of Environmental and Life Sciences, \\ pl. Grunwaldzki 24, 50-363 Wroclaw, Poland \\ ${ }^{\mathrm{b}}$ Institute of Building Engineering, Wroclaw University of Technology, Wybrzeze Wyspianskiego 27, 50-370 \\ Wroclaw, Poland
}

Received 2 February 2006

Revised April 2007

\begin{abstract}
This paper describes laboratory tests carried out in the steel flat-bottomed silo model filled with sand, subjected to external dynamic loads. The model was placed on a system of springs, which represent subsoil. The loads in the form of horizontal impulses were applied to the bottom plate of the silo. Horizontal pressure-time courses were used to analyze the influence of subsoil vibrations on the distribution changes of these pressures. Basic conclusion: (1) the subsoil vibrations cause two types of changes of the horizontal pressures: stable changes which are observed when the model vibrations finish and cyclic of short duration (brief) changes; (2) the subsoil vibrations either generate stable increase or stable decrease of the pressures from before vibrations or do not generate any essential stable change; (3) the cyclic dynamic changes of the horizontal pressures depend on the direction of the silo wall displacements and they are the function of the values of these displacements.
\end{abstract}

Keywords: Silo model test, granular material, dynamic pressure measurement, vibration

\section{Introduction}

Not much has been known on the subject of behavior of silos and bulk materials stored into them subjected to subsoil vibrations in despite of permanent interest of the anti-seismic engineering. Up to now only few papers referring to this subject have been published. The most important theoretical papers are listed in Table 1. Wellestablished techniques were published by Braun and Eibl [1] and Younan and Veletsos [11,12]. In both theoretical models which allow to determine the distribution of bulk material pressures acting on silo wall and stresses within stored bulk material were presented. Papers about experimental tests on this subject are even fewer. Among them papers of Sasaki and Yoshimura [9] and Sakai et al. [8] contain results in the form of dynamic pressure distributions acting on the silo wall. Figure 1 shows discrepancies between the pressure distributions shown by above mentioned authors. As can be seen from this Figure there exist large differences between individual data. One of the reasons can be complicated nonlinear properties of bulk materials and mutual relations between their characteristics. The basic difficulty is to the formulate far-going assumptions concerning constitutive relations. They are necessary to solve equations. Moreover, in the case of numerical model, entirely pure numerical constitutive parameters have to be used. Constitutive parameters of the bulk materials have often decisive influence on the final result. Results of experimental tests which are carried out on the models of reduced scale models, generally are not possible to transferred on real objects due as scale effect. On the other hand test on real objects present technical-operating and often financial difficulties.

*Corresponding author. Tel.: +48 7132055 29; Fax: +48 713205584. 
Table 1

Setting up of theoretical papers

\begin{tabular}{|c|c|c|c|}
\hline Authors & System model & Model of bulk material & Type and form of results \\
\hline Braun and Eibl 1995 & $\begin{array}{l}\text { numerical, 3D, structure analy- } \\
\text { sis in time }\end{array}$ & nonlinear, hypoplastic & time courses of all result \\
\hline Younan and Veletsos 1998 & $\begin{array}{l}\text { analytical, 3D, with wall flexi- } \\
\text { bility, harmonic shock }\end{array}$ & $\begin{array}{l}\text { linear viscoelastic, } \\
G=\text { constans } \\
D=\text { constans }\end{array}$ & $\begin{array}{l}\text { spatial distribution courses of nor- } \\
\text { mal and shear stresses, and displace- } \\
\text { ments depending on time }\end{array}$ \\
\hline Hardin et al. 1996 & $\begin{array}{l}\text { numerical, 2D, shear beam, } \\
\text { modal analysis }\end{array}$ & $\begin{array}{l}\text { nonlinear, viscoelastic, } G(\gamma) \text { and } \\
D(\gamma) \text { as hysteresis, } G(\gamma) \text { and } D(\gamma) \\
\text { depend from bulk material depth in } \\
\text { silo }\end{array}$ & $\begin{array}{l}\text { distribution of shear stresses and } \\
\text { nondilational strains along to silo } \\
\text { height, impossible to determine of } \\
\text { the dynamic horizontal pressures of } \\
\text { bulk material }\end{array}$ \\
\hline Van Wijk 1993 & $\begin{array}{l}\text { analytical, } 2 \mathrm{D}, \text { shear beam, } \\
\text { method of response spectrum }\end{array}$ & $\begin{array}{l}\text { nonlinear, viscielastic, } G(\gamma) \text { and } \\
D(\gamma) \text { as hysteresis, }\end{array}$ & $\begin{array}{l}\text { distribution of maximal shear, } \\
\text { stresses, nondilational strains and } \\
\text { displacements along to silo height, } \\
\text { impossible to determine of the dy- } \\
\text { namic horizontal pressures of bulk } \\
\text { material }\end{array}$ \\
\hline $\begin{array}{l}\text { Ciesielski and Dulińska } \\
199219941995\end{array}$ & numerical, 3D, modal analysis & - & $\begin{array}{l}\text { envelopes of internal forces in si- } \\
\text { lo shell, impossible to determine of } \\
\text { the dynamic horizontal pressures of } \\
\text { bulk material }\end{array}$ \\
\hline
\end{tabular}

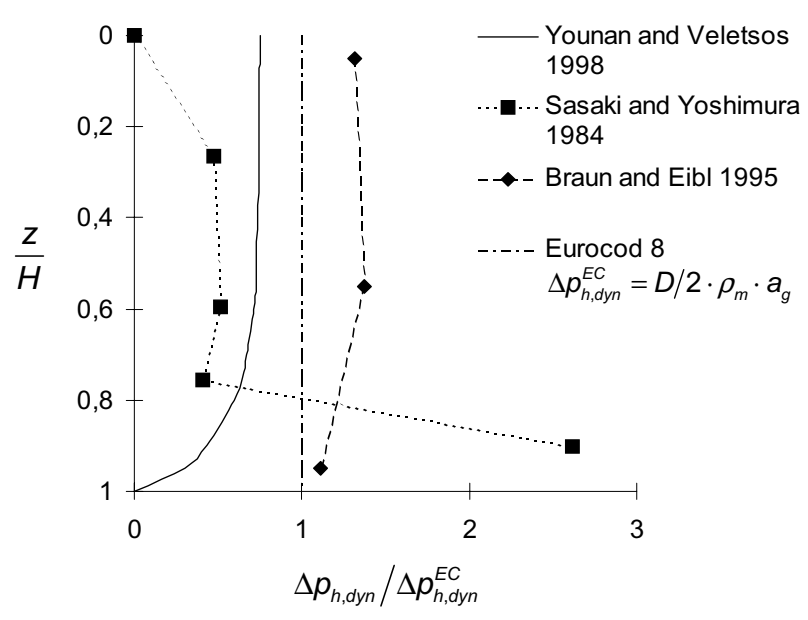

Fig. 1. Comparison of horizontal pressure distributions according to various authors.

\section{Research significance}

Due to a small number of publications directly concerning influence of subsoil vibrations on horizontal bulk material pressure on silo wall and the lack of univocal response on the question: what happens with these pressures during silo vibrations, the aim of the present work is to register and describe the changes of the dynamic horizontal pressures caused by the subsoil vibrations and to determine the influence of the dynamic load level and the subsoil stiffness on pressures.

\section{Test setup and test program}

Test setup presented on Fig. 2 contained a steel flat-bottom silo model of $1200 \mathrm{~mm}$ height, $400 \mathrm{~mm}$ diameter and $4 \mathrm{~mm}$ thick wall. The model bottom - a $10 \mathrm{~mm}$ thick steel plate, was supported on a spring system. The basic test stand elements were: test silo, charge bin, impact device for excitation of the impulse loads as well as pressure cells, 


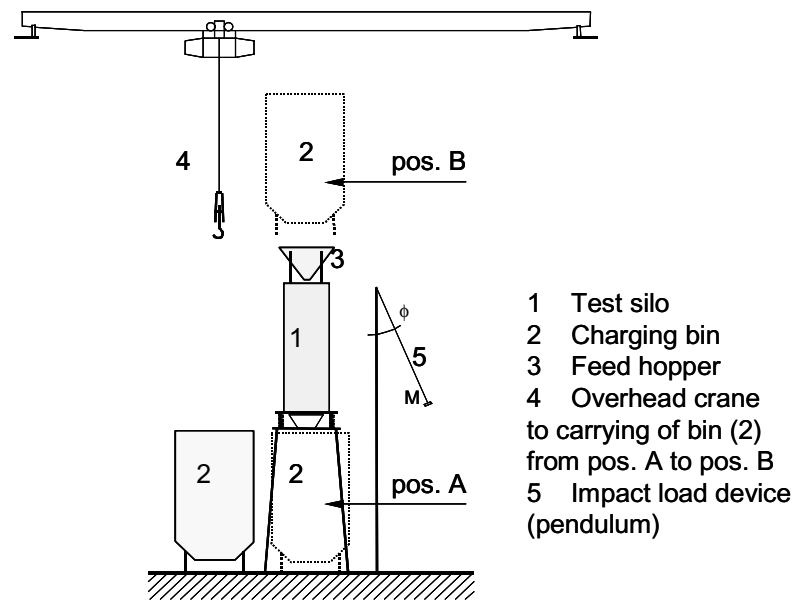

Fig. 2. Test stand.

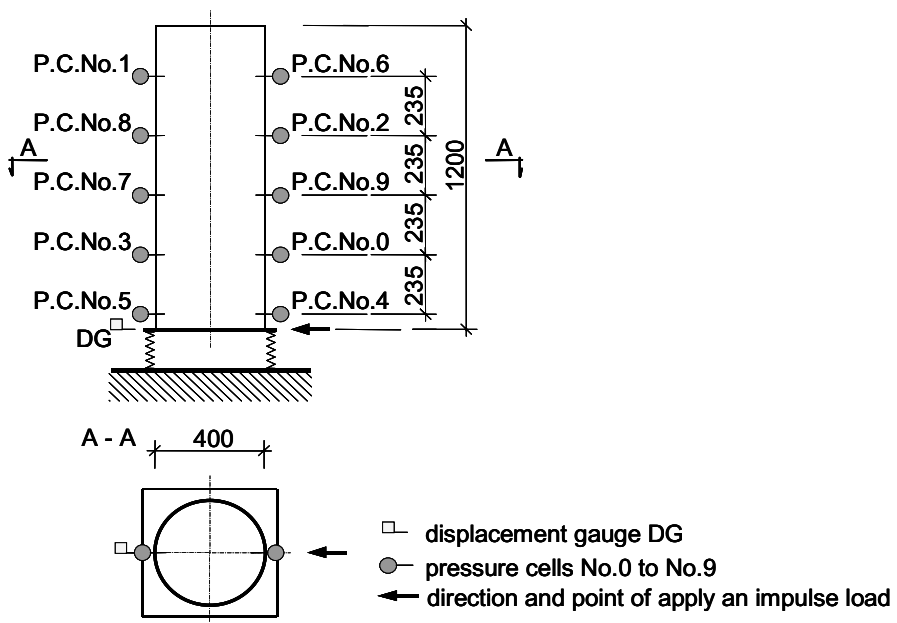

Fig. 3. Arrangement of pressure cells on model.

transducer and a computer. Dynamic loads were generated by a ballistic pendulum in the form of a single impulse horizontally applied to the bottom plate. This pendulum is characterized by its length, inclination angle and variable mass. Quantities describing the dynamic loading were: maximum horizontal amplitude measured by the inductive gauge and horizontal pressures acting on the silo wall measured by ten pressure cells installed, for five along each of two opposite vertical generatrix (Fig. 3). For the sake these tests the membrane cells were made with the measuring elements in the form electric resistance wire gauges. Bulk material used for the tests was fractional coarse grained sand with the size of 0.4 to $1.2 \mathrm{~mm}$. For the purpose of subsoil modeling of different dynamic properties two springs systems of different stiffness were used.

Two model test groups $P$ and $S$ differing in the dynamic coefficient of subsoil were carried out. In each group for four measuring series of different values of impulse load were performed. The test program is presented in Table 2. In each cycle the following were performed: pressure cells zero adjustment, filling out with sand of the test silo, registering the static pressures, starting the "continuous" record of pressures and displacements, striking the test silo by pendulum and emptying the silo after recording the test. 
Table 2

Test program

\begin{tabular}{lccccccccc}
\hline Group: & & $\mathrm{P}$ & $\mathrm{P}$ & $\mathrm{P}$ & $\mathrm{P}$ & $\mathrm{S}$ & $\mathrm{S}$ & $\mathrm{S}$ & $\mathrm{S}$ \\
\hline Dynamic modulus of subgrade reaction & {$\left[\mathrm{kN} / \mathrm{m}^{3}\right]$} & 5.4 & 5.4 & 5.4 & 5.4 & 6.6 & 6.6 & 6.6 & 6.6 \\
\hline Serie: & & $40 \mathrm{P}$ & $60 \mathrm{P}$ & $80 \mathrm{P}$ & $100 \mathrm{P}$ & $40 \mathrm{~S}$ & $60 \mathrm{~S}$ & $80 \mathrm{~S}$ & $100 \mathrm{~S}$ \\
\hline Acceleration amplitude & {$\left[\mathrm{m} / \mathrm{s}^{2}\right]$} & 0.67 & 1.20 & 1.69 & 2.24 & 0.57 & 1.05 & 1.47 & 2.11 \\
\hline
\end{tabular}

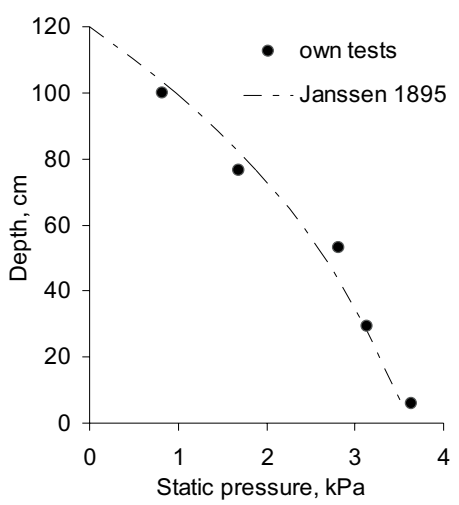

Fig. 4. Setting up of experimental results of static pressures.
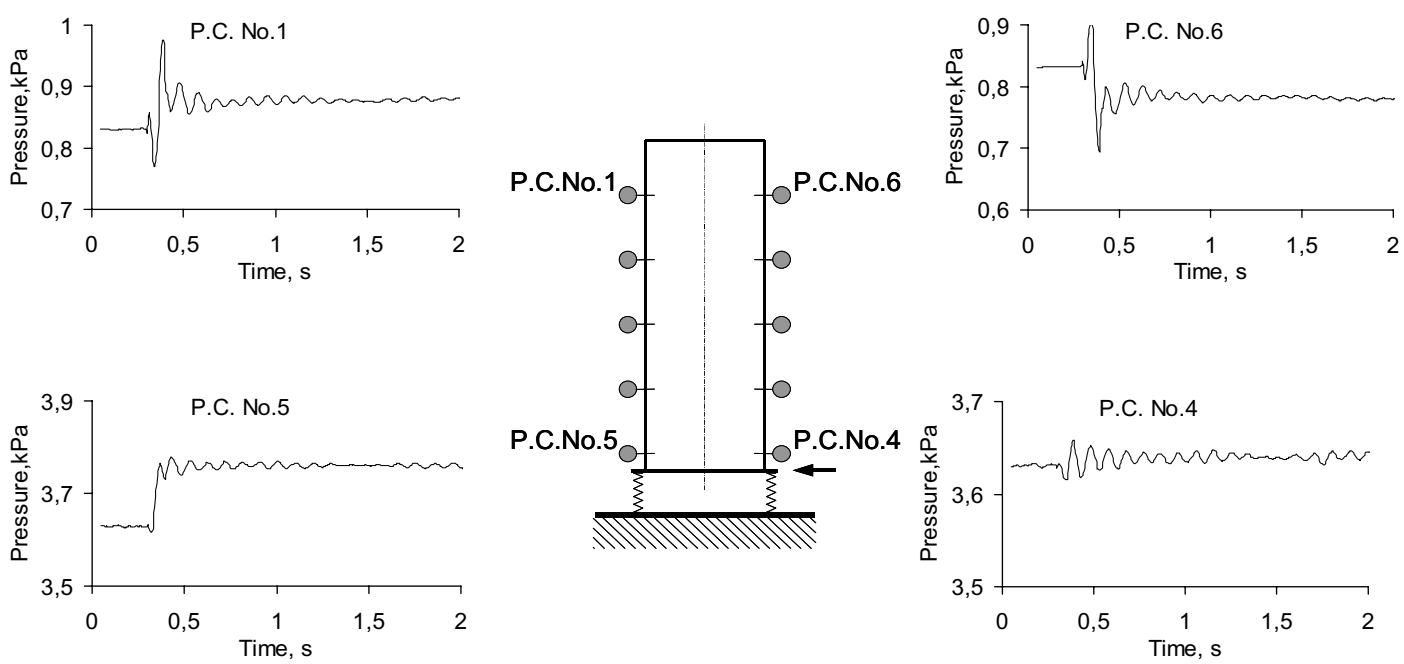

Fig. 5. Time histories of pressures for series 80P.

\section{Test results}

The starting point of the analysis of the dynamic pressures are static pressures the courses of which for the chosen cells are presented on Fig. 4. Mean values of these pressures represent reference point for all changes of dynamic bulk material pressures. The illustration of the obtained measurement results selected from 160 measuring cycles are initial fragments of bulk material pressure time histories which are represented on Figs 5 and 6.

\section{Analyses of test results}

Due to the model wall thickness, foundation type and loading type, the dynamic characteristic of emptied or filled silo, was limited to two silo vibration modes: translational and rotational (Fig. 8). The harmonic analysis of the 

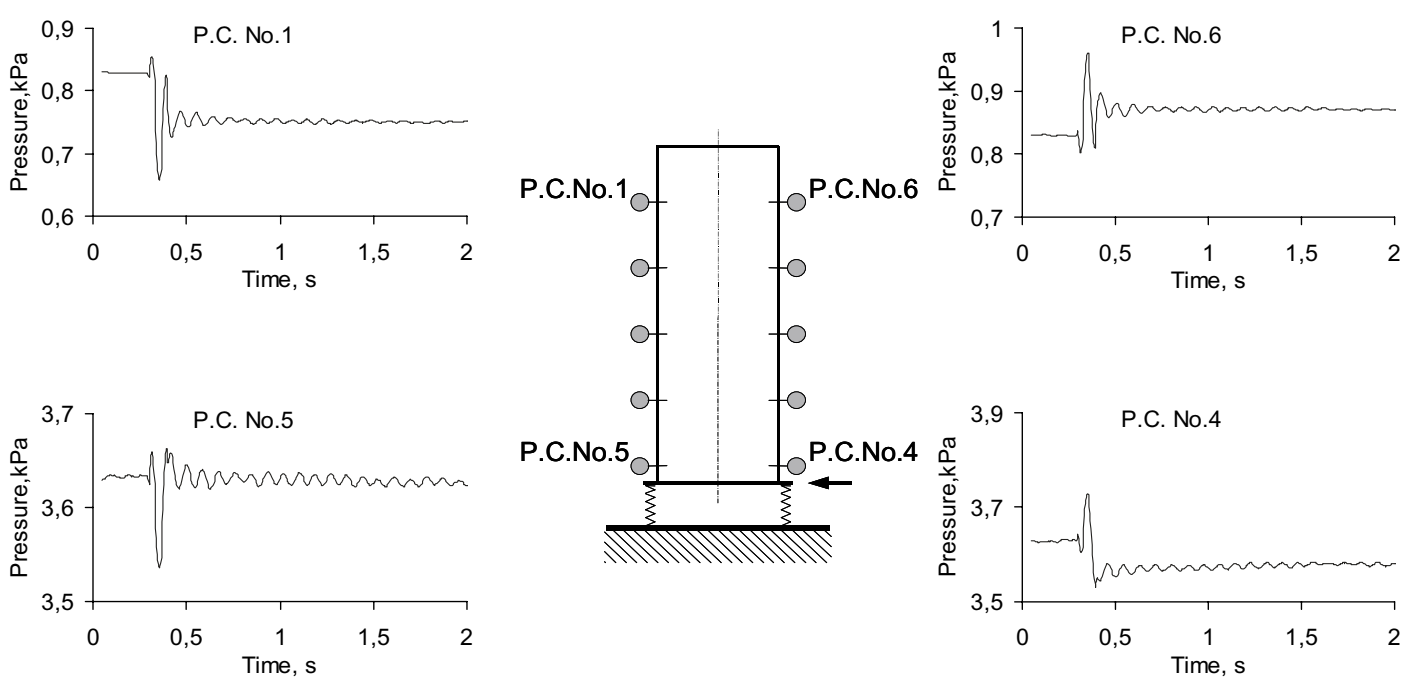

Fig. 6. Time histories of pressures for series $80 \mathrm{~S}$.
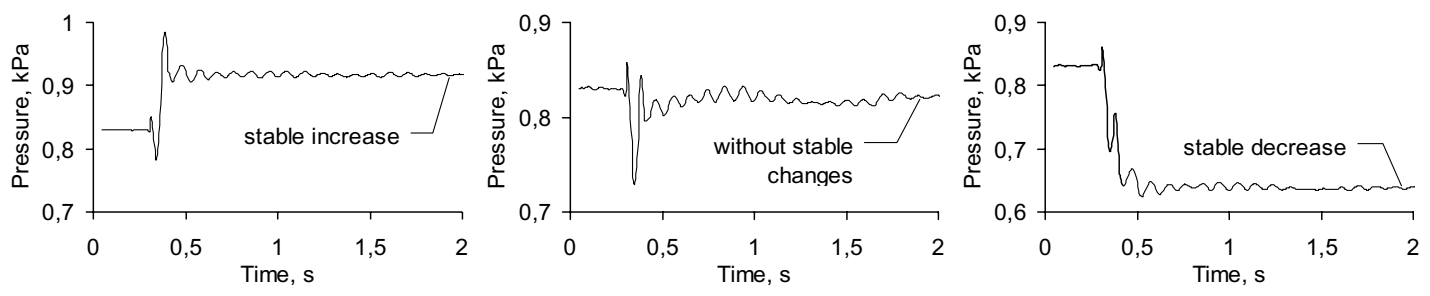

Fig. 7. Nature of stable changes of pressures (series 60P, P.C. No.1).

acceleration diagrams shows that the fundamental frequencies of natural vibrations are adequately equal 10.4 and $11.5 \mathrm{~Hz}$ for both types of subsoil ( $P$ and $S$ series). Maximum bulk material pressure changes for all levels of the dynamic loading and both types of the subsoil appear in the initial phase of silo model vibration, at about 0.2 second after load application. In the phase of damped vibrations a stabilization of level pressure occurs. Silo vibrations either produce stable increase or stable decrease of bulk material pressure values in relation to their level before the load impact, or do not produce any fundamental pressure changes of a stable character (Fig. 7). Not stated existence of univocal dependences between location of measuring points along to silo height and level as well as character of final pressure. Also, not found mutually dependencies between these pressures. The stable finish changes of dynamic bulk material pressures oscillate in the range of $1 \%$ to $10 \%$ of the static pressures values. A phenomenon of general character, observed in each cycle and in all the measuring points, was the dependence of cyclic bulk material pressure changes upon directions of the silo wall displacements. When a wall moved away from the bulk material then the pressures decreased, and when the wall moved towards the bulk material, they increased. The correlation coefficients of the silo model base displacements and bulk material pressures confirm the existence of this dependence. Absolute values of these coefficients are included in the range of 0.70 to 0.94 . The correlation is positive when displacements of the silo base result in the increase of pressure. But correlation is negative if increase of silo base displacement result in decrease of pressure. Distribution of correlation coefficient signs, presented on Fig. 8, confirmed the fundamental meaning of the rotational free vibration in the dynamic characteristic of the silo model. Further analysis of the test results was based on the absolute values of the extreme pressure amplitudes obtained in particular measuring cycles. Highest dynamic pressure changes appear in the range of $2 \%$ to $20 \%$ and $2 \%$ to $37 \%$ of static pressure values adequately for $P$ and $S$ series, respectively. Distributions of the dynamic pressure along silo height differ in significant manner from the distributions assumed in Eurocode 8. Differences concern both pressure values and diagram form. As can be seen in Figs 9 and 10 the relationship dynamic pressure-depth in 
Theoretical zones of horizontal pressure changes for free vibration models
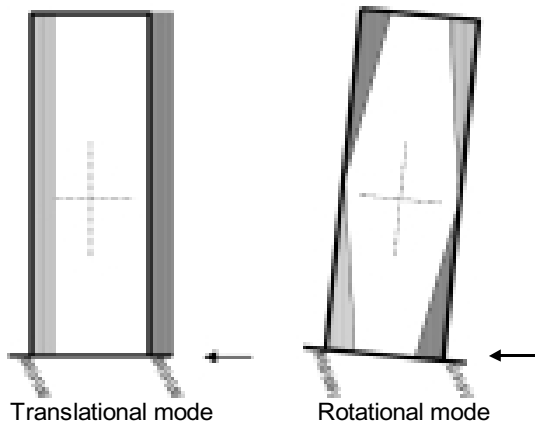

zone of pressure increase and positive correlation
Signs distribution of correlation coefficients

for particular measuring points

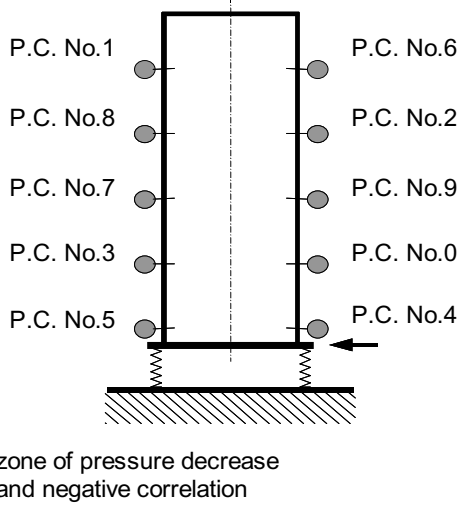

Fig. 8. Dependence of pressure change from displacement direction of silo wall and correlation of model base displacements and horizontal pressures.
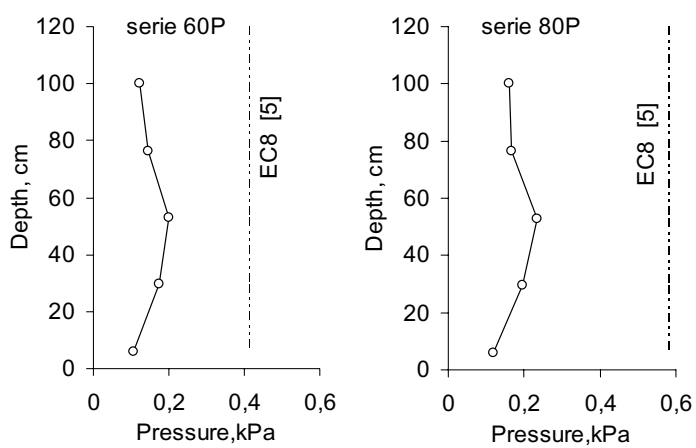

Fig. 9. Distribution of maximal dynamic pressures for P series.

each case of loading and subsoil type, is nonlinear. To determine the mean effect of subsoil vibration on the values of bulk material pressures the mean values of maximum dynamic pressures for all measuring series, were estimated. It was found that these pressures are included in the range of $26 \%$ to $56 \%$ and $43 \%$ to $72 \%$ of standard pressures, for $P$ and $S$ group, respectively. Correlation curves of the acceleration-dynamic pressure relationship have been shown in Fig. 11. These dependencies are the power functions. Correlation coefficients are equal 0.997 and 0.985 , respectively. Test results demonstrating the existence of subsoil stiffness effect on the horizontal pressure caused by the vibration are presented in Table 3. The differences of the dynamic subsoil coefficients $C_{x}$ both models was equal $22 \%$. Meanwhile, differences of the dynamic pressure value for the particular subsoil models are equal from $17 \%$ to $66 \%$ depending on the amplitude acceleration values. Because the springs applied in the model did not satisfy the conditions of model similarity, therefore it is not possible to draw out quantitative conclusions concerning the subsoil stiffness effect on pressure values.

\section{Conclusions}

Tests concern to changes of the horizontal pressure of the material on a silo wall caused by subsoil disturbance carried out in the Laboratory of Building Engineering Institute, Wroclaw University of Technology allowed to make out the following conclusions:

1. The silo vibrations produce a stable increase or stable decrease of the pressures in comparison with their value before the disturbance, or they do not produce any substantial pressure changes of the stable character. The 
Table 3

Effect of subsoil stiffness on dynamic pressure

\begin{tabular}{cccc}
\hline $\begin{array}{c}\text { maximum acceleration } \\
\text { amplitude of subsoil }\end{array}$ & $\begin{array}{c}\text { mean dynamic horizontal } \\
\text { pressure in P series }\end{array}$ & $\begin{array}{c}\text { mean dynamic horizontal } \\
\text { pressure in S series }\end{array}$ & difference \\
\hline $\mathrm{A}\left[\mathrm{m} / \mathrm{s}^{2}\right]$ & $\mathrm{p}_{\mathrm{h}}[\mathrm{kPa}]$ & $\mathrm{p}_{\mathrm{h}}[\mathrm{kPa}]$ & {$[\%]$} \\
\hline 0.5 & 0.1130 & 0.1317 & 17 \\
1.0 & 0.1458 & 0.1980 & 36 \\
1.5 & 0.1693 & 0.2513 & 48 \\
2.0 & 0.1882 & 0.2976 & 58 \\
2.5 & 0.2043 & 0.3393 & 66 \\
\hline
\end{tabular}
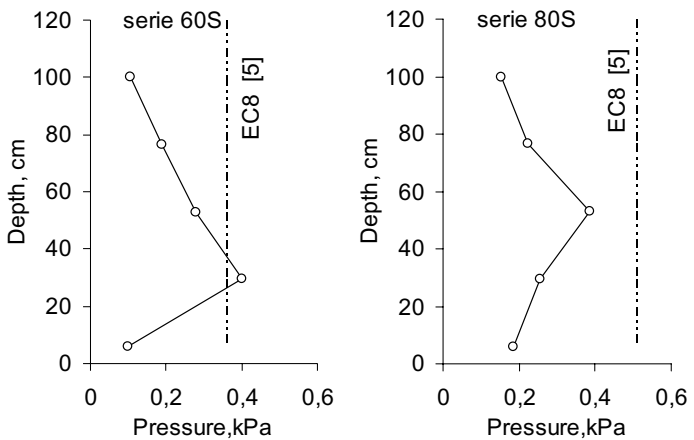

Fig. 10. Distribution of maximal dynamic pressures for $\mathrm{S}$ series

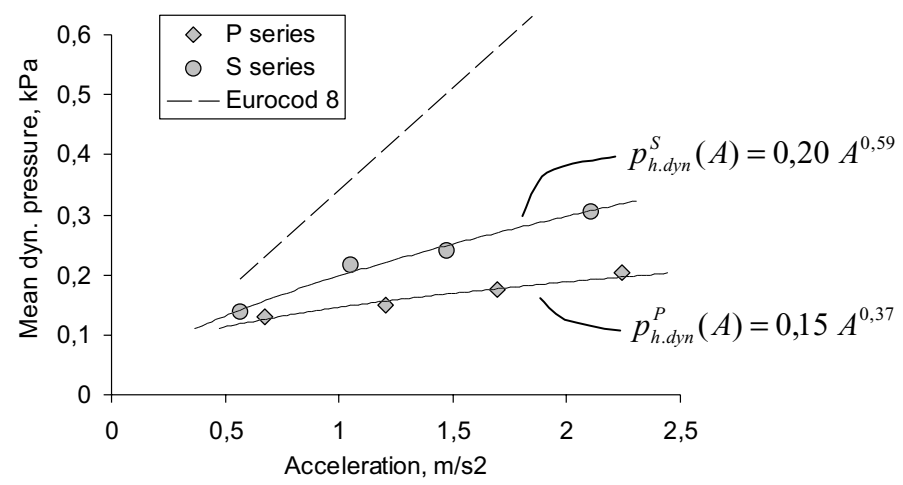

Fig. 11. Relationship of mean dynamic pressure-acceleration amplitude.

existence of univocal relationships between the localization of measuring points along the silo height and the level as well as the course of final pressures or mutual relationships between these pressures, have not been found.

2. Dynamic pressures changes depend on the displacement direction of the silo wall and are the function of that displacement.

3. Distribution of the maximum dynamic pressures along the silo height is nonlinear.

4. The relationship of mean horizontal dynamic pressure of bulk material acting on a silo wall and the maximum acceleration amplitude of subsoil is a nonlinear dependence.

5. Pressures caused by subsoil vibrations depend on dynamic subsoil stiffness.

\section{References}

[1] A. Braun and J. Eibl, Silo pressures under earthquake loading, X International Conference on Reinforced and Post-tensioned Concrete Silo and Tanks, Cracow, 1995, 21-28. 
[2] R. Ciesielski and J. Dulińska, Response analysis of cylindrical reinforced concrete silo under paraseismic disturbance, IX Conference on Reinforced and Post-tensioned Concrete Silo and Tanks, Wrocław-Szklarska Poręba, 13-35.

[3] R. Ciesielski and J. Dulińska, Analysis of paraseismic influences on selected structures of rotational-symmetrical types, VII Symposium on Seismic and Paraseismic Influences on Structures, Cracow, 1994, 179-190.

[4] R. Ciesielski and J. Dulińska, Response comparison of rotational-symmetrical tanks on paraseismic influences for different disturbance modes, X International Conference on Reinforced and Post-tensioned Concrete Silo and Tanks, Cracow, 1995, 13-20.

[5] Eurocode 8, Design Provision for Earthquake Resistance of Structures.

[6] B.O. Hardin, R.A. Bucklin and I.J. Ross, Shear-beam analysis for seismic response of metal wheat bins, Transactions of the ASAE 39(2) (1996), 677-687.

[7] H.A. Janssen, Versuche über Getreidedruck in Silozellen, Zeitschrift des Vereins deutscher Ingenieure 39(35) (1895), 1045-1049.

[8] M. Sakai, H. Matsumura, M. Sasaki, N. Nakamura, M. Kobayashi and Y. Kitagawa, Study on the dynamic behavior of coal silos against earthquakes, Bulk Solids Handling 5(5) (1985), 1021.

[9] Y. Sasaki and J. Yoshimura, Dynamic behavior of concrete stave silos, Proceedings of the 8th World Conference on Earthquake Engineering, 1984.

[10] L.A. Van Wijk, Earthquake resistance of mammoth silos of the Eurosilo type, PhD Thesis, University of Twente, Enschede, 1993.

[11] A.H. Younan and A.S. Veletsos, Dynamics of solid-containing tanks, I: rigid tanks, Journal of Structural Engineering 124(1) (1998), $52-61$.

[12] A.H. Younan and A.S. Veletsos, Dynamics of solid-containing tanks, II: flexible tanks, Journal of Structural Engineering 124(1) (1998), $62-70$. 

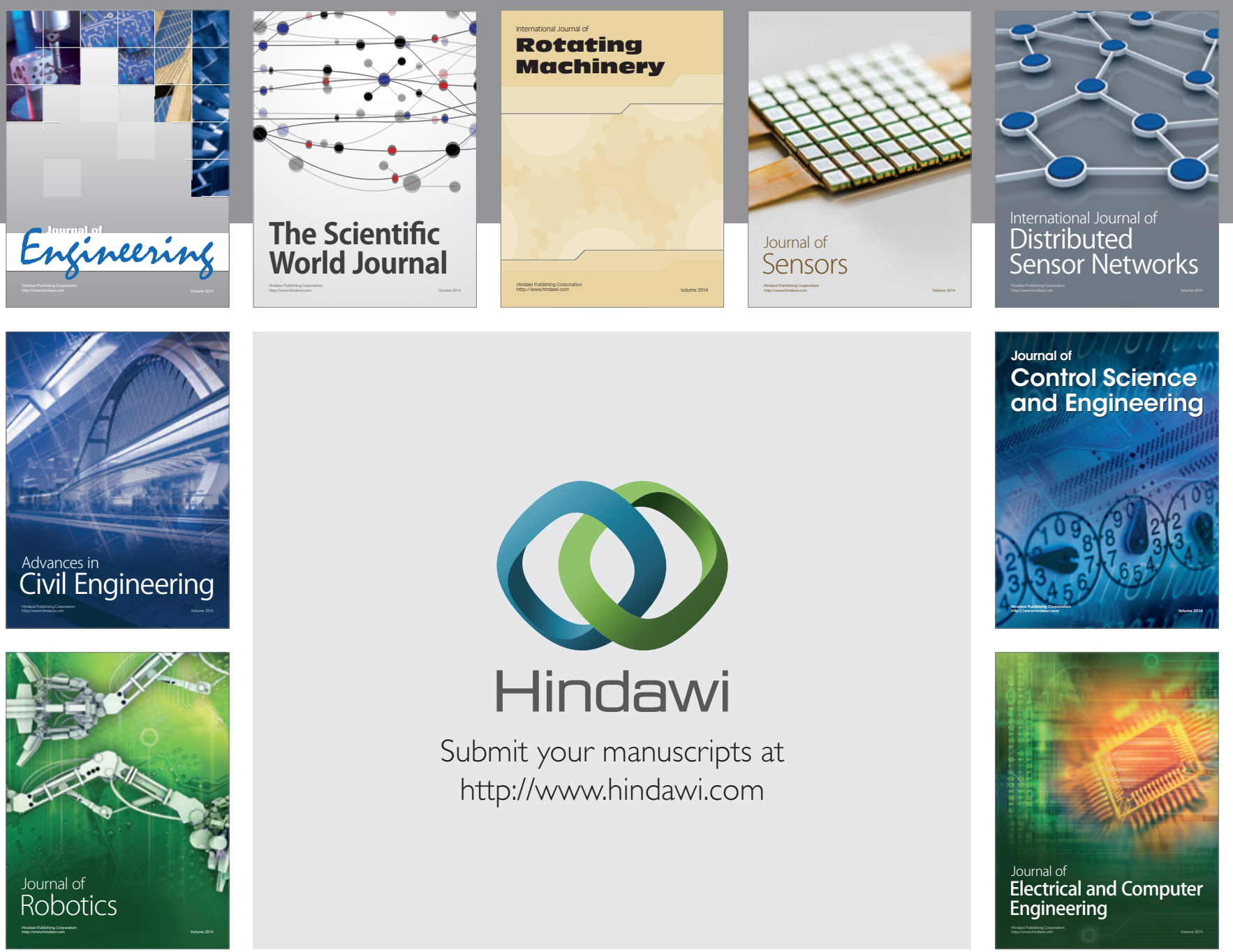

Submit your manuscripts at

http://www.hindawi.com
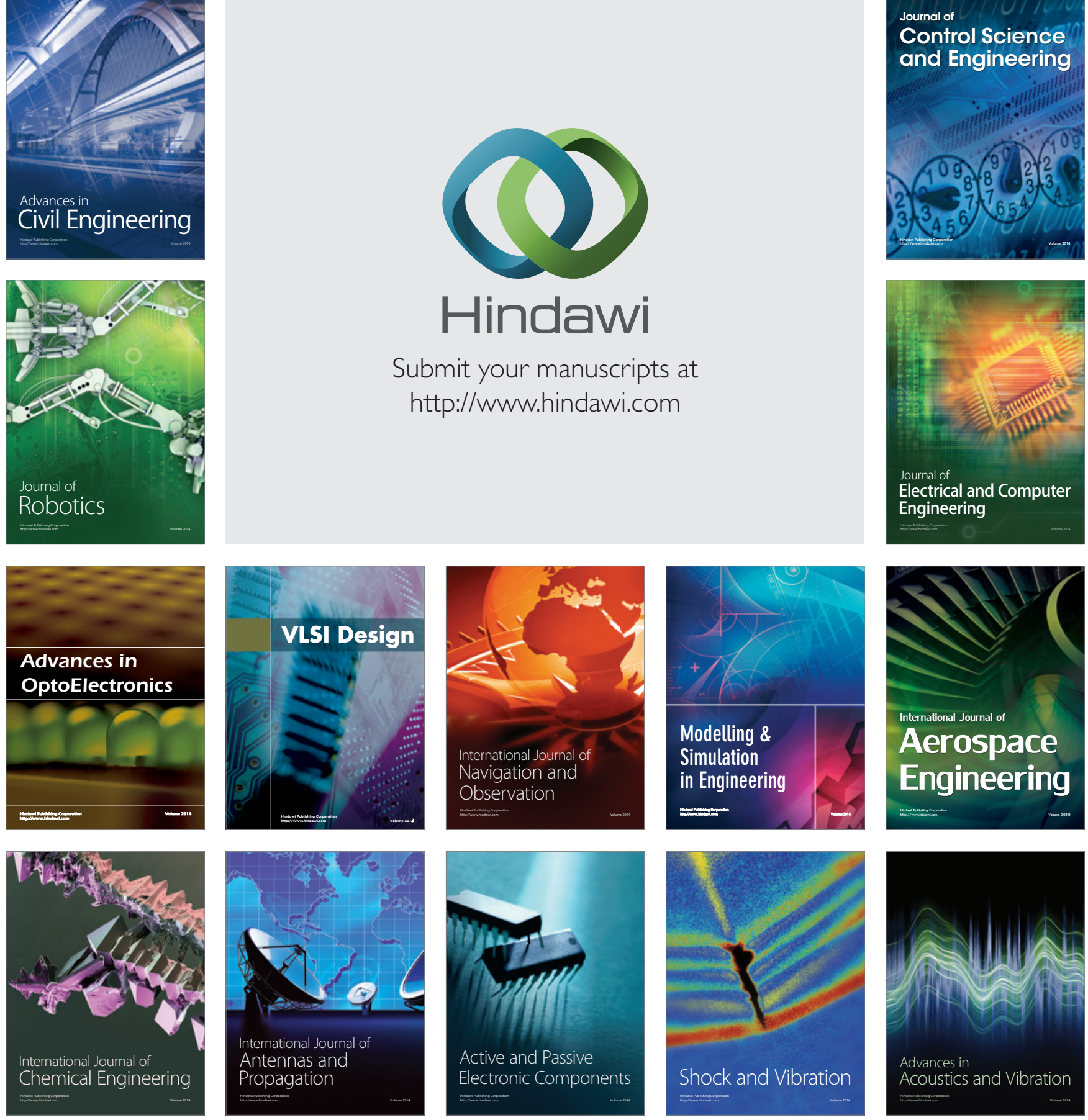